\title{
Economic and social benefits of a strategy of ecological monitoring for oil and gas companies operating in the Russian Arctic
}

\author{
Ishel Bianco ${ }^{1, *}$, Alexander Illinskyi ${ }^{2}$, and Alexey Fadeev ${ }^{2,3}$ \\ ${ }^{1}$ Universiy of Maryland, 20742, Maryland, USA \\ ${ }^{2}$ St. Petersburg Polytechnic University in the name of Peter the Great, St. Petersburg, Russia \\ ${ }^{3}$ Institute of Economic Problems named after G.P. Luzin FRC KSC RAS, Apatity, Murmansk region, \\ Russia
}

\begin{abstract}
Ecological monitoring provides a more complete picture of the possible effects of extractive activities for oil and Gas companies operating in the Russian Arctic and in other ecological sensitive areas. This paper proposes a framework to evaluate the adequacies of different monitoring systems for Operations in the Arctic for oil and Gas companies. Our research also demonstrates how Ecological monitoring could be a useful strategic tool for long term risk reduction, accident avoidance and to improve the socioeconomic development for indigenous communities.
\end{abstract}

\section{Introduction}

The Arctic is a very fragile environment characterized by harsh and unpredictable conditions, the risks of operations for Oil and Gas companies are very high due to the consequences of ecological damage that can translate into severe damage for renewable resources and impairing destruction of rare species. As traditional fields and hydrocarbon resources dry, the Russian Arctic where of the oil and gas is presented becomes has become a focus of exploration for oil and gas [1].

Different extractive companies use different types of monitors to measure the impacts of their activities in the environment and to prevent disasters, particularly in ecologically sensitive areas like the Arctic regions. Arctic Regions also present greater challenges in remediation due to the scarcity of resources and the high significance of very few species as well as slower rates of biodegradation.

In coordination with chemical and physical indicators, ecological-biological indicators provide a richer picture of environmental impacts over three and four dimensional space. Exploration in complex ecosystems require more integrative systems of monitoring in the form of multispecies sensor arrays and networks. Ecological/Multispecies Biological monitoring provides with a far more complete picture of the consequences of extractive activities in particular of oil and gas extraction, specifically related to biomes that provide valuable climatic and renewable resources from which Arctic populations depend [2].

\footnotetext{
${ }^{*}$ Corresponding author: ishel.bianco@bfgllc.net
} 


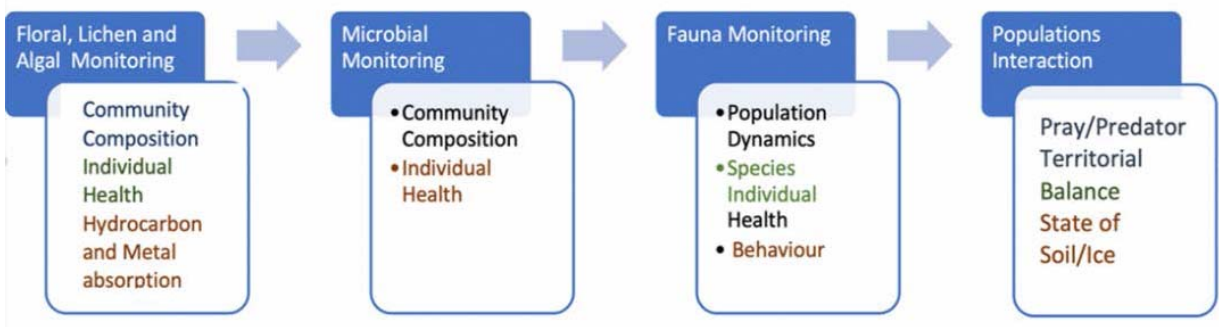

Chemical and Physical sensors near source

Fig. 1. Ecological monitoring structure.

\section{Methods}

In this study we employ mathematic, and statistics method including correlation and ANOVA

This study integrates several fields, economics, ecology, technology, data and petrochemistry.

To be able to quantify the benefits of investment on ecological monitoring we first defined the type of costs that an oil company might incur and it calculates the average of a spill or disaster in a particular area,

First, we define the costs of an accident.

Average cost of accident o spill in vulnerable ecological area as referred to cleaning Di

The immediate cleaning of an accident or Arctic spill is complicated by difficult access to site due to climatic conditions, also immediate labor might be rare of poorly trained. Gazprom and Rosneft have very comprehensive oil spill management plan but any plan in the Arctic might have higher costs because the way oil affects snow or Arctic environments has been poorly researched in comparison to other ecosystems.

Average cost of spill in vulnerable ecological area as defined by remediation and restoration efforts Drr

The costs of remediation and restoration in the Arctic are staggering, first because of the harsh conditions encountered in the Arctic seas, which permit restoration work only at certain times of the year, and these also might be variable, ice conditions such as breaking of icebergs even in warming climates increases risks of conditions, as do certain types of snow and ice $[2,3]$.

Average cost of accident or spill as reflected on shareholder value.

This cost varies from company to company, some companies, especially Russian and Chinese companies like Gazprom, Rosneft and Sinopec, are less sensitive to shareholders backlash about ecological accidents, moreover this effect is reduced by the absence of high fines in a more relaxed regulatory environment.

Average cost of company restructuration because of accident, represented as financial and management costs.

Many companies such as BP and Exxon Mobile fired some of the management, engineers and broke alliances with service companies after a significant accident, these costs are also reflected on the loss of shareholder value but not included in this calculation, as lack of stability affect the confidence of shareholders.

We also define the quality of the different kinds of indicators subject of surveillance, we rank them In their accuracy, in their relevance to ecosystem services and their reliability as time of effective work, complexity and finally immediacy of information defined as the 
promptness by which indicators can be evaluated where $\mathrm{Ccl}$ cost of cleaning, $\mathrm{Crm}$ Cost of Remediation, $C f$ Cost of Finance, times the Vulnerability of the Region Index $V u l$ [3]

$$
\text { Costs of Accidents and Spills in the Arctic }=(C c l+C r m+C f) * V u l
$$

Then we define the parameters to measure and qualify them by impact:

- Chemical Indicators

Sensors for chemicals have been used in many industries, although some of them give an incomplete picture as the ones shown in the Canadian tar sands. The indicators show that pollution is lower because of the location at which they have been sent and their spacing. Chemical indicators can be less relevant to some organism than others and therefore produce an incomplete picture of the ecosystem damage a chemical produces, this is more acute where there is bioaccumulation and where some life stages might be affected that are crucial to the survival of a species [4].

- Physical indicators

These can be obtained by satellite, drones and robotics, these indicators might be ineffective in some climatic conditions, these indicators might also misread the type of hydrocarbons involved on an accident. Physical indicators have medium to high accuracy depending on the technology involved. Physical indicators might also not be very relevant to the ecosystem in question, for example deep spills might not be visible if their composition is of heavier oils and they might sink quickly to the bottom or they might mix with other particles, making it difficult to evaluate its effects. Cost of physical operations vary but are higher in the Arctic [1, 5].

- Ecological and Biological indicators.

These indicators are more complex and therefore might require more steps to be properly deployed analyzed and maintained. The personnel using them might require more training, fortunately there are technological solutions that can rapidly interpret these indicators to sign an alarm, in this sense the immediacy factor of ecological and biological indicators is enriched by its factor of complexity. The costs here are technology, and man hours which would be normally be priced high, however cooperation between educational institutions, NGO's and oil companies can reduce these costs significantly and maximize benefits $[6,8]$.

We evaluate these methods as an average of Reliability(Re), Immediacy(Im), and $\operatorname{Accuracy}(A c)$, multiplied by Relevance(Re) and divided by $\operatorname{Cost}(C)$, and Complexity(Com) obtaining the Value created to the company

$$
\text { Value of sensor }=\frac{(A C+R e l+I m) * R e}{C+C o m}
$$

\section{Social Value of Ecological Monitoring}

Economic activity of Oil and Gas in the Arctic requires infrastructure, this infrastructure can give significant contributions to the well- being of Arctic communities. Furthermore, oil and gas companies can benefit from fostering education programs, often non extractive activities are damaged because of the effect of pollutants, disturbance and population movement which have further effect on indigenous cultures. Some oil companies who operate in the Arctic have already addresses community impacts, however, this is often done by separating the cultures from their ecosystem. Gazprom has created the program "Hometowns" which created projects ranging from city infrastructure(175), education(58), and the protection of cultural heritage(27), they include stakeholder involvement and use volunteers and company talent showing leadership on integration of factors[15].

Many communities in the Arctic are dependent on renewable resources, indigenous communities have cultural practices that are linked to the natural resources that may have shown to be affected by oil and gas activities. These vulnerabilities is increased with their 
dependency as an index, for example if a culture is a pastoralist herding elk and elk feeds on 3 or 4 species of lichens, and that lichen is affected by carbon intake, monitoring the quantities of carbon in the air might be crucial for their survival. Monitoring lichen's health might be a better predictor because of the many chemical and environmental interactions in biological systems. Least populous cultures that have a lower economic level might be also be overexposed to ecological risk would their more important resources suffer significant resources. An oil company also might be able to monitor better the state of migrating herds or for prey animals because they might have sensors in far station and areas that are hard to reach. Gazprom in Russia has a monitoring program for walrus populations, bears and Norwal wales that produces large quantity of data at more frequent intervals than academic expeditions [2,7].

Careful environmental monitoring preserves root cultural identity linked to natural resources. Oil and Gas development that is respectful of renewable resources can lead to an investment on the human capital of the local area, leading to a higher income for the community, better health, lower mortality and better communication technology. It is important to try to include all of the possible factors that can affect the long- term wellbeing of Arctic communities after extractive resources have been depleted since renewability has limitations. The socio-Economic value of environmental monitoring can be measured in long time spans often multigenerational. [2,8]. The principal Indicators are the quality of natural Resources and the creation of long-term perspectives of development for their population.

Social Value of Ecological Monitoring = Dependence of Population on each Natural Renewable Resources, here represented as Fishing (Df), Hunting (Dh), Forest $(D f o)$, Herding $(D h)$, Soil Quality $(S q) *$ Territory $(T e)$ /Population $(P)$ which is considered the vulnerability for each population + infrastructure Investment (Inv), Costs of Development, here defined as detrimental changes to the renewable resources during establishment of environmental strategy(CostD) mentioned above mitigation(Mit).

The dependence values are estimated as GDP per income of activity times percentage of activity or total income per activity. Soil quality is assessed by productivity of soil. All values are estimated on the lifetime of the project.

$$
\begin{gathered}
\text { Social Value of EcoMonitoring }=(D f+D h+D f o+D h+S q) * \frac{T e}{p}+I n v- \\
(\operatorname{Cost} D-M i t)
\end{gathered}
$$

\section{Results}

The results show that oil and gas companies that actively engage in the monitoring of the health ecosystems in sensitive areas such as the Arctic, do not only become more acceptable in the local community but also may increase profitability by avoiding costly disasters, expensive restoration, and pollutant fees, altogether they also become more agile and efficient managing risks that can severely thwart further projects.[7] To avoid risks is essential to monitor the indicators such as plant cover, nutrient deposition on bacterial communities and the health of wildlife.

The benefits of proactive monitoring for oil and gas companies are influenced by the life cycle of projects, and they form a process that can have long consequences on the environment, the communities and the company itself. Investments might take a long time to mature in tangible competitive advantages for the company, but companies like Equinor have seen investment in technologies transform into a technological advantage that is not restrained to the first area where it was used, companies like Shell who have trained locals have seen lower costs of transfers of labor, Gazprom itself has developed educational programs that have translated into development and retention of talent. 


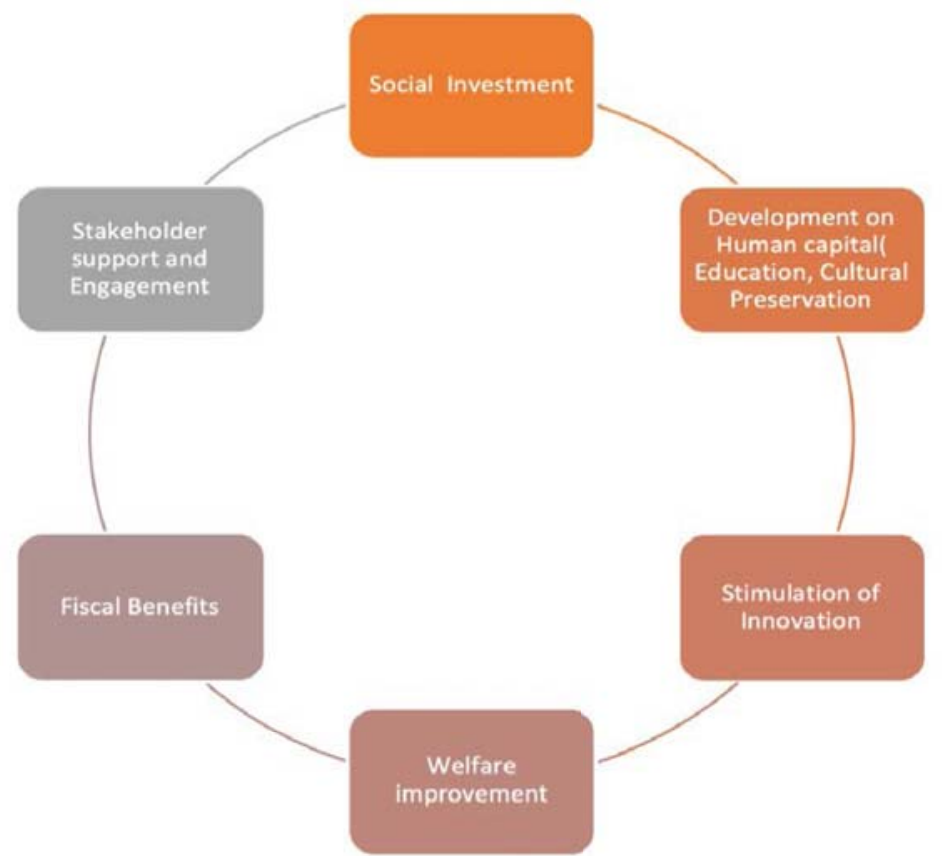

Fig. 3. Oil and Gas Investment cycle. Source, Authors [7].

The study indicates that oil and gas companies can derive greater benefits from environmental than of just chemical monitoring the ecosystem since living organisms provide for a more comprehensive review of effects such as auditory interference, saturations of some chemicals and the associated bacteria that might thrive because of it.

Table 1. Type of Monitoring.

\begin{tabular}{|l|c|c|c|c|c|c|}
\hline $\begin{array}{l}\text { Type of } \\
\text { Monitoring }\end{array}$ & $\begin{array}{c}\text { Accuracy } \\
\boldsymbol{A c}\end{array}$ & $\begin{array}{c}\text { Relevance } \\
\boldsymbol{R} \boldsymbol{E}\end{array}$ & $\begin{array}{c}\text { Reliability } \\
\boldsymbol{R} \boldsymbol{e l}\end{array}$ & $\begin{array}{c}\text { Complexity } \\
\boldsymbol{C o m}\end{array}$ & $\begin{array}{c}\text { Immediacy } \\
\boldsymbol{I M}\end{array}$ & $\begin{array}{c}\text { Cost } \\
\text { C }\end{array}$ \\
\hline Chemical & High(4) & Medium(3) & High(4) & Low(2) & High(4) & Low(2) \\
\hline Physical & Low(2) & Medium(3) & Low (2) & Low(2) & High (4) & Medium(3) \\
\hline $\begin{array}{l}\text { Ecological } \\
\text { Biological }\end{array}$ & High(4) & $\begin{array}{c}\text { Very } \\
\text { High(5) }\end{array}$ & Medium(3) & High(4) & Medium(3) & Medium \\
\hline
\end{tabular}

While the results show that in environments like the Arctic ecological-biological monitoring is more effective, there are different areas within one site that might require more chemical or physical monitoring. Some areas might also have a higher level of biodiversity, while others might be scarcely used except at sometimes of the year, because of that, areas that more fragile because of the kind of species encountered should have a different valuation reflecting the higher immediacy. Therefore, the earlier equation should be changed where in areas where immediate response is critical.

$$
\text { Value of Monitorig System at High Immediacy }=\frac{(A c+R e l)^{R e+I m / 2}}{C+C o m}
$$

The combination of sensors to be used also might be influenced by the availability which will change the value of complexity, as new technologies develop or the training to use data becomes more standardized the complexity level might further be reduced. The perfect mix of sensors is to be reached by several factors, vulnerability of the species and the affectation 
of possible accident or discharge of pollutants, the availability of technology and financial considerations of the operator.

Finally, the information obtained by Environmental monitoring can easier delineate the strategy of development in the oil field. If the information obtained shows that the impacts of human activity are too high, a strategy of minimization can be put into place.

We have formed a strategy that illustrates the distribution of benefits of environmental monitoring.

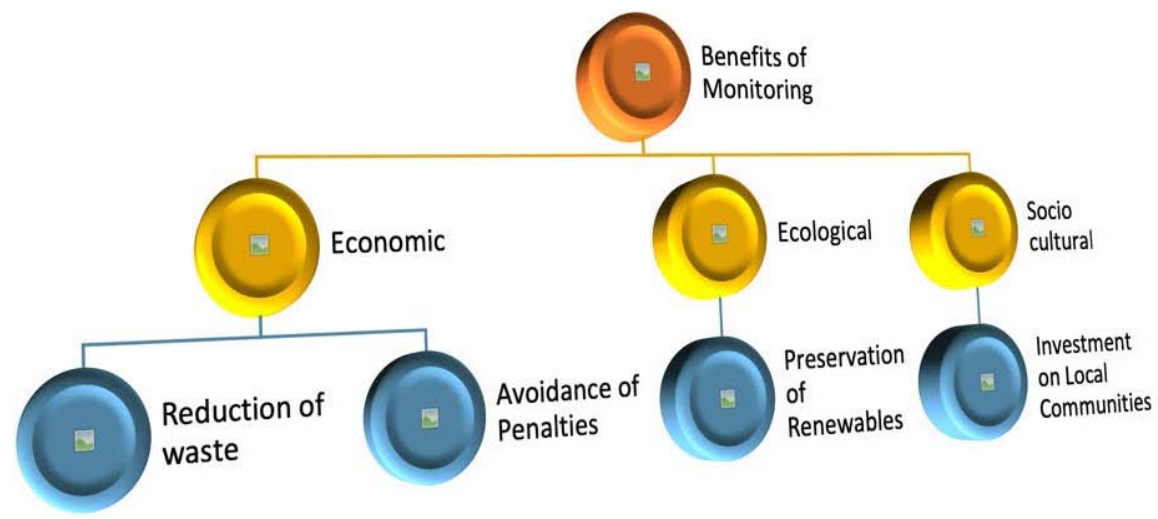

Fig. 2. Breakdown of benefits of monitoring [2].

\begin{tabular}{lr}
\hline \multicolumn{2}{c}{ Regression Statistics } \\
\hline Multiple R & 0.99214646 \\
R Square. & 0.9843546 \\
Adjusted R Square & 0.9687092 \\
Standard Error & 87.2757181 \\
Observations & 5 \\
\hline
\end{tabular}

\begin{tabular}{|c|c|c|c|c|c|}
\hline & df & SS & MS & $\mathrm{F}$ & Significance F \\
\hline Regression & 2 & 958477.084 & 479238.542 & 62.9165465 & 0.0156454 \\
\hline Residual & 2 & 15234.102 & 7617.05098 & & \\
\hline Total & 4 & 973711.186 & & & \\
\hline
\end{tabular}

\begin{tabular}{lrrrrrr}
\hline & Coefficients & Standard Error & \multicolumn{1}{c}{ t Stat } & \multicolumn{1}{c}{ P-value } & \multicolumn{1}{c}{ Lower 95\% } & Upper 95.0\% \\
\hline Intercept & 652.541341 & 199.306334 & 3.27406223 & 0.0819799 & -205.0046 & 1510.08728 \\
X Variable 1 & 0.02707429 & 0.00305078 & 8.8745315 & 0.01246041 & 0.01394782 & 0.04020075 \\
X Variable 2 & -0.0278764 & 0.00574158 & -4.8551842 & 0.03990003 & -0.0525805 & -0.0031724
\end{tabular}

Fig. 3. Results of Regression.

The results of the regression strongly indicate that the best risk reduction strategy would be to reduce the amount of land used, since this relates stronger with a reduction of the fees than any other factor including general investment on safety measures. Although the observations are few, they present a consistent picture that can be used for descriptive purposes. The general investment on new technology might not immediately reflect as they are do not reflect the kind of technology used which might be effective to diminish the risks of spills and other accidents. From our observations from the years 2014-2019 from Gazprom, we establish that we could predict the fees incurred based on the elements of 
Investment in environmental monitoring and the amount of Land disturbed. The correlation with the Land used is negatively significant, 0.89 and the reaction with Investment is mildly strong. 0.60

Table 2. Environmental Risk reduction in the Arctic.

\begin{tabular}{|l|l|l|l|}
\hline \multicolumn{1}{|c|}{ Strategy } & \multicolumn{1}{c|}{ Advantages } & \multicolumn{1}{c|}{ Disadvantages } & \multicolumn{1}{c|}{ Results } \\
\hline Minimization & $\begin{array}{l}\text { Lower Cost } \\
\text { Lower Waste }\end{array}$ & $\begin{array}{l}\text { Some unexplored } \\
\text { opportunities might remain }\end{array}$ & $\begin{array}{l}\text { Higher profits by reduction in } \\
\text { costs }\end{array}$ \\
\hline Target & More accuracy & $\begin{array}{l}\text { Some risks might be } \\
\text { overlooked }\end{array}$ & $\begin{array}{l}\text { Higher profits by more } \\
\text { focused profit centers }\end{array}$ \\
\hline Partnership & Dynamism & $\begin{array}{l}\text { Dispersion of responsibility } \\
\text { might still mean high } \\
\text { accountability }\end{array}$ & $\begin{array}{l}\text { Lower costs but higher risks, } \\
\text { difficulty on response } \\
\text { coordination. }\end{array}$ \\
\hline Mitigation & Intensiveness & $\begin{array}{l}\text { Not proper for areas of high } \\
\text { ecological vulnerability } \\
\text { Higher uncertainty }\end{array}$ & $\begin{array}{l}\text { Short term higher profits } \\
\text { Higher insurance costs }\end{array}$ \\
\hline
\end{tabular}

\section{Discussion}

The combination of sensors to be used also might be influenced of availability and adequacy in the specific location, which will change the value of complexity in our equation as new technologies develop or the training to use data becomes more standardized the complexity level might further be reduced. The perfect mix of sensors is to be reached by several factors, vulnerability of the species and the affectation of possible accident or discharge of pollutants, the availability of technology and financial considerations of the operator. In addition, long term, the use of ecological monitoring can reduce expenses for Oil by reducing losses of valuable hydrocarbons, reducing the risk of accidents, improving maintenance regimes that can be impacted by biological activity and migrations and by reducing the consequent costs of remediation and restoration after the close of operations [10]. More accurate environmental impact evaluation can benefit Oil and Gas companies operating in the Arctic by increasing stakeholder involvement, increasing company valuation, reducing insurance expenses as well as penalties for environmental damage.

Finally, the information obtained by Environmental monitoring can easier delineate the strategy of development in the oil or gas field. If the information obtained shows that the impacts of human activity are too high, a strategy of minimization can be put into place. Technologies such as directional and horizontal drilling as well as recent technologies that minimize drilling space reduce the environmental footprint of extractive operations $[11,14]$.

A target strategy would mean that there is intensive development in some areas with more geological promise minimizing overall impact, and that the information used for the Environmental Management plan would focus on the species or region only, however, this strategy could understate or miss the consequences in adjacent areas or populations.

The Socio-Cultural benefits of social monitoring will be larger for communities that are heavily dependent on resources that require ecosystem's health and integrity such as fisheries, to protect them it is essential that we develop better frameworks to assess the consequences of economic activity in the Arctic. Low income communities are disproportionately affected by damage to renewable resources. Although changes will happen that can be negative, also positive changes for example using infrastructure in order to facilitate communication among native stakeholders may take place and strengthen their representation in decision making. This is particularly important in regions of high immediacy. The oil spills in Norilsk, Kamchatka and in Israel in 2020 and 2021 showed the need for rapid intervention and the consequences of not acting in time $[15,16]$. 
Partnerships can help bring different expertise and diversify the risks that an incident might affect one company, disproportionally however large disasters like the Exxon Valdez and the Deep Well Horizon still affected the parent companies even if they outsourced the process because it was linked to the larger company strategy.

In the Case of Gazprom our analysis shows that the greatest predictor of penalties and fees, her one of the most tangible indicators of damage to the environment, is the amount of land disturbed, investment on environmental monitoring is also a considerable factor. This indicates that Gazprom and other companies operating in the Arctic achieve their lowers risk when they choose a minimization strategy together with a target strategy.

Russia has extensive oil and gas reserves, and Gazprom has a very effective remediation rate more than $93 \%$ for observed parameters, however, the Arctic presents singular challenges, phyto-bioremediation and rhizoremediation are more effective at higher temperatures [15].

Further data should be collected in the rest of the factors that could influence accidents and legislation that would make violations costlier and more uniform among Arctic nations.

In the future the authors of this study want to focus on the economic benefits for oil and gas companies of the use of ecological monitoring and the use of specific technologies to make more accurate predictions and recommendations. More studies are needed to better evaluate the relations between quality of life and ecological protection in the Arctic. Because of the conjunction of long species timeframes in particular for many species in the arctic and the long term cycles of investment for oil and gas companies, data of at least 25 years will be far more useful, unfortunately some environmental indicators have only been recorded for the last 5 years. Si From our observations from the years 2014-2019 from Gazprom, we establish that we could predict the fees incurred based on the elements of Investment in environmental monitoring and the amount of Land disturbed. The correlation with the Land used is negatively significant, 0.89 and the reaction with Investment is midly strong. 0.60

From our observations from the years 2014-2019 from Gazprom, we establish that we could predict the fees incurred based on the elements of Investment in environmental monitoring and the amount of Land disturbed. The correlation with the Land used is negatively significant, 0.89 and the reaction with Investment is midly strong. 0.60

\section{Conclusions and Recommendations}

Our study shows that the conditions of the Arctic require a more holistic monitoring strategy for the consequences of the extractive industries such as the Oil and gas industry. The use of Chemical and Physical sensors alone is less accurate to the effects of normal operations and extraordinary incidents such as spills and accidents than ecosystem and biological monitoring.

Ecological-Biological monitoring can help a company devise a better strategy for operations in the Arctic, the most likely strategy will be a combination of Minimization and Targeting which offer lower risks in such a complex area.

The larger economic benefit to oil and Gas companies will be a reduction of costs and a minimization of risks of extraordinary or low likelihood-high cost events. Everyday operations may also be marginally benefit from environmental monitoring [2].

The socio-economic benefits of Ecological-Biological monitoring improve the welfare of the local communities by protecting renewable resources that have historically sustained, preserving their cultures and by encouraging innovation and economic participation [13].

From our observations from the years 2014-2019 from Gazprom, we established a model that could predict the fees incurred based on the elements of Investment in environmental monitoring and the amount of Land disturbed. 
The best risk reduction strategy will also depend of the use of technology as impacts land, surface waters or ice disturbed. This strategy can also be coordinated with international monitoring where questions of common safety.

Reduction of land use could reduce the amount of disturbance to indigenous communities by maintaining the integrity of their renewable resources such as fishing, herding and hunting stock [16].

\section{References}

1. D. Estrin, W. Michener, G. Bonito et al, Environmental cyberinfrastructure needs for distributed sensor networks: a report from a national science foundation sponsored workshop (Scripps Institution of Oceanography, La Jolla, CA, USA, 2003)

2. J.R. Caputo, D. Cella U. Gandelli, A. Alippi, C. Grimaccia F. Zich, Proceedings of the Wireless Sensor and Actuator Network Research on Opposite Sides of the Globe (SENSEI) (Stockholm, Sweden, 2008)

3. SDG Compass: The guide for business action on the SDGs (GRI, UN Global Compact and World Business Council for Sustainable Development, 2016)

4. J. Montewka, M. Weckström, P. Kujala, Gulf of Finland Pollution Bulletin 76(1-2), 6171(2013) ISSN 0025-326X

5. T. Le Goff, J. Braven, L. Ebdon, D. Scholefield, J. of Env. Mon. 5, 353-358 (2003)

6. V.G. Krasnopolskiy, Neftegaz. 5, 104-110 (2019)

7. B. Weinhold, Environmental health perspectives 119(3), 126131 (2011)

8. A.E. Cherepovitsyn, T.A. Chvileva, N.V. Romasheva, Int. J. Civ. Eng. Technol. 9, 938948 (2018)

9. M. Kruk, A. Semenov, A. Cherepovitsyn, A. Nikulina, Eur. Res. Stud. J. 21, 423-433 (2018)

10. A. Fadeev, Improvement of economic approaches to the management of Arctic marine hydrocarbon fields development (KSC RAS, Apatity, 2012)

11. A. Fadeev, A. Ilynsky, I. Iliyin, IOP Conf. Series: Earth and Environmental Science 539, 012168 (2020)

12. B. Malashenkov, L. Akchurin, Moscow University Bulletin. Management (state and society), $\quad 2(21), \quad 49-64 \quad$ (2015) $\quad$ http://www.spa.msu.ru/ uploads/files/stati/malashenkov_akshurin.pdf

13. A. Evseev, T. Krasovskaya, V. Tikunov, I. Tikunova, ISPRS Int. J. of Geo-Inf. 8, 357 (2019) DOI: 10.3390/ijgi8080357

14. A. IIiinsky, M. Afanasiev, D. Metkin, IOP Conference Series: Materials Science and Engineering 497, 012028 (2019) DOI: 10.1088/1757-899X/497/1/012028

15. Gazprom. Gazprom Reports, https://www.gazprom.com/nature/environmental-reports

16. R.J. Brulle, D.N. Pellow, Annu. Rev. Public Health 27, 103-124 (2006) 